\title{
sciendo
}

\section{THE EFFECT OF FERMENTED SOYBEAN MEAL ON PERFORMANCE, BIOCHEMICAL AND IMMUNOLOGICAL BLOOD PARAMETERS IN TURKEYS*}

\author{
Robert Chachaj ${ }^{1}$, Iwona Sembratowicz ${ }^{1}$, Magdalena Krauze ${ }^{1 \star}$, Anna Stępniowska ${ }^{1}$, Elżbieta Rusinek- \\ Prystupa $^{1}$, Anna Czech ${ }^{1}$, Paulius Matusevičius ${ }^{2}$, Katarzyna Ognik ${ }^{1}$
${ }^{1}$ Department of Biochemistry and Toxicology, Faculty of Animal Sciences and Bioeconomy, University of Life Sciences in Lublin, Akademicka 13, 20-950 Lublin, Poland
${ }^{2}$ Department of Animal Nutrition, Lithuanian Veterinary Academy, Lithuanian University of Health Sciences, Tilzes 18, 47181 Kaunas, Lithuania •Corresponding author: magdalena.krauze@up.lublin.pl

\begin{abstract}
The aim of the present study was to assess the effect of different levels of fermented soybean meal on growth performance, intestinal morphology, metabolic indicators, and immunity in turkeys. The material for the study consisted of day-old BIG 6 turkeys raised to the age of 112 days. The experiment was carried out on 800 turkey hens (10 replications of 20 individuals each), assigned to 4 experimental groups of 200 birds each. The feed for the control group (FSBM $)_{0}$ was a standard mix without fermented soybean meal. For turkeys from groups FSBM, FSBM $_{9}$ and FSBM FSe $_{10}$ diet contained 70, 90 or $100 \mathrm{~g}$ fermented soybean meal (FSBM) per $\mathrm{kg}$ of feed, respectively. The study showed that including fermented soybean meal in feed for turkeys at $7 \%$ improved intestinal histology and stimulated the immune and antioxidant systems. The use of higher level of FSBM $(9 \%$ and $10 \%)$ in the diet of the turkeys improved growth performance and had a beneficial effect on the histology of the small intestine. The dietary inclusion of $10 \%$ FSBM had beneficial effect on red-blood-cell parameters, but caused negative impact on liver and kidney function (an increase of aminotransferases activity, content of glucose and creatinine in turkeys' blood). Ten percent share of FSBM in feed contributed to an adverse intensification of oxidation and inflammatory reactions which were reflected by an increase of malonyldialdehyde, lipid peroxides level and proinflammatory inteleukine- 6 contents.
\end{abstract}

Key words: fermented soybean meal, turkey, immune status, histology

Soybean meal (SBM) is the most commonly used protein source in animal diets (Liu et al., 2007). However, a lot of anti-nutritional factors (ANFs), such as trypsin inhibitors, galactooligosaccharides, lectins, and allergenic proteins have limited the

*This research was partially supported by FeedStar Ltd., Poland and European Protein, Denmark. Work financed from ZKT/DS3. 
application of SBM in poultry feed, especially for young poultry. Fermentation process is one of the effective methods for processing of plant-based protein meals. It has been observed that fermentation enhances the nutritional value of feed through the biosynthesis of vitamins, essential amino acids and protein, by improving protein quality and fibre digestibility (Adetuyi and Ibrahim, 2014). It is believed that the fermentation process of soybean meal results in a significant reduction (by $80 \%$ ) of the ANF content and an increase in the proportion of digestible phosphorus to $80 \%$. In addition, this process favours the enrichment of the raw material with vitamins and minerals, as well as allows for a $15 \%$ more effective release of vegetable protein, rich in essential amino acids, especially methionine, lysine and threonine, and small peptides (e.g. glutathione) that can further increase the nutritional value of supplemental fermented soybean meal (FSBM) (Hong et al., 2004; Hur et al., 2014; Kim et al., 2010; Zhang et al., 2013).

Moreover, the fermentation process enriches the product with beneficial microorganisms (e.g. live Lactobacillus cultures) and the bioactive substances they produce. The inclusion of fermented products in monogastric animals feed has been shown to induce beneficial effects on growth performance and gastrointestinal health by exhibiting probiotic activity and could therefore be treated as an alternative for antibiotic growth promoters (Missotten et al., 2015). Feng et al. (2007 a) reported that feeding of FSBM contributed to a significant increase in the activities of digestive enzymes (trypsin, lipase, and protease) in intestinal contents of broiler chickens. Fermented feed may reduce the $\mathrm{pH}$ of the digestive tract and thereby inhibit the growth of populations of pathogenic bacteria, and also may improve the histology of the intestines (Mathivanan et al., 2006). High content of lactic acid bacteria and bioactive peptides, as well as antioxidant compounds, in fermented meal as compared to unfermented meal may modulate immune response (Feng et al., 2007 b; Xu et al., 2011). The fermentation process contributes to lowering the level of soy allergens (glycinin, ß-conglycinin, and trypsin inhibitors), and the use of FSM reduces the risk of food hypersensitivity reactions (Liu et al., 2007). The beneficial effects of application of fermented protein meals (soya, rapeseed or faba beans) on performance and general health of different poultry species are well documented (Drażbo et al., 2018 a; Jazi et al., 2018; Xu et al., 2011). However, the available literature lacks precise data on the effect of dietary use of fermented soybean meal in on the health and performance of turkeys.

In view of the above, the aim of this study was to verify the hypothesis postulating that the fermentation of soybean meal added to turkey diets has a beneficial influence on the growth performance, metabolic indicators, immune status and morphometry of the intestines of turkey.

\section{Material and methods}

\section{Source of fermented soybean product}

Fermented soybean meal (FSBM) from European Protein (Bække, Denmark) were used in the study. FSBM was prepared from soya by-products, i.e. solvent- 
extracted soybean meal (SBM, containing $470 \mathrm{~g} / \mathrm{kg} \mathrm{CP}$ ). Fermentation was carried out by Lactobacillus plantarum strain. The growth medium for bacteria consisted of potato starch, potatoes and wheat. The composition of the FSM and FSBM is presented in Table 1.

Table 1. Composition of non-fermented soybean meal (SBM) and fermented soybean meal (FSBM)

\begin{tabular}{lcc}
\multicolumn{1}{c|}{ Item } & SBM & FSBM \\
\hline Ingredients (g/kg) & & 895 \\
dry matter & 897.2 & 505 \\
crude protein & 470.5 & 22 \\
crude fat & 19.9 & 34 \\
crude fibre & 35.8 & 64 \\
crude ash & 64.5 & 114 \\
non-starch polysaccharides (nsp) & 124.3 & $<5$ \\
raffinose & 45 & 74 \\
lactic acid & 1.95 & 27.9 \\
lysine & 24.6 & 6.9 \\
methionine & 5.8 & 19.8 \\
threonine & 17.4 & 6.4 \\
tryptophan & 6.2 & 6.86 \\
Lactobacillus $($ log CFU/g) & 4.22 & $<0.5$ \\
TIA* (mg/g) & 2.86 & $<2$ \\
B-conglycinin (mg/g) & 58.94 & \\
\hline
\end{tabular}

*TIA - trypsin inhibitors.

\section{Animals}

The material for the study consisted of day-old BIG 6 turkeys raised to the age of 112 days. The experimental procedure was approved by the Second Local Ethics Committee for Experiments with Animals in Lublin (approval no. 30/2016). Turkeys were raised in pens on litter until 16 weeks of age in a building with a controlled environment, and they had free access to feed and water (Smulikowska and Rutkowski, 2005). The experiment was carried out on 800 turkey hens assigned to 4 experimental groups of 200 birds each (10 replications of 20 individuals each). During each of 4 feeding phases, birds were fed ad libitum isonitrogenous and isocaloric diets in pellet form. The feed for the control group $\left(\mathrm{FSBM}_{0}\right)$ was a standard mix without fermented soybean meal. The diet for turkeys from groups $\mathrm{FSBM}_{7}, \mathrm{FSBM}_{9}$ and FSBM 10 contained 70, 90 or $100 \mathrm{~g}$ fermented soybean meal per $\mathrm{kg}$ of feed.

The diets were prepared in the Trouw Nutrition (Poland). The nutritional value of diets was consistent with the nutrient requirements of turkeys (British United Turkey). Table 2 presents the composition of control and experimental diets prepared in succession per feeding period and Table 3 presents calculated nutritional value according to Polish Feedstuff Analysis (Smulikowska and Rutkowski, 2005). 


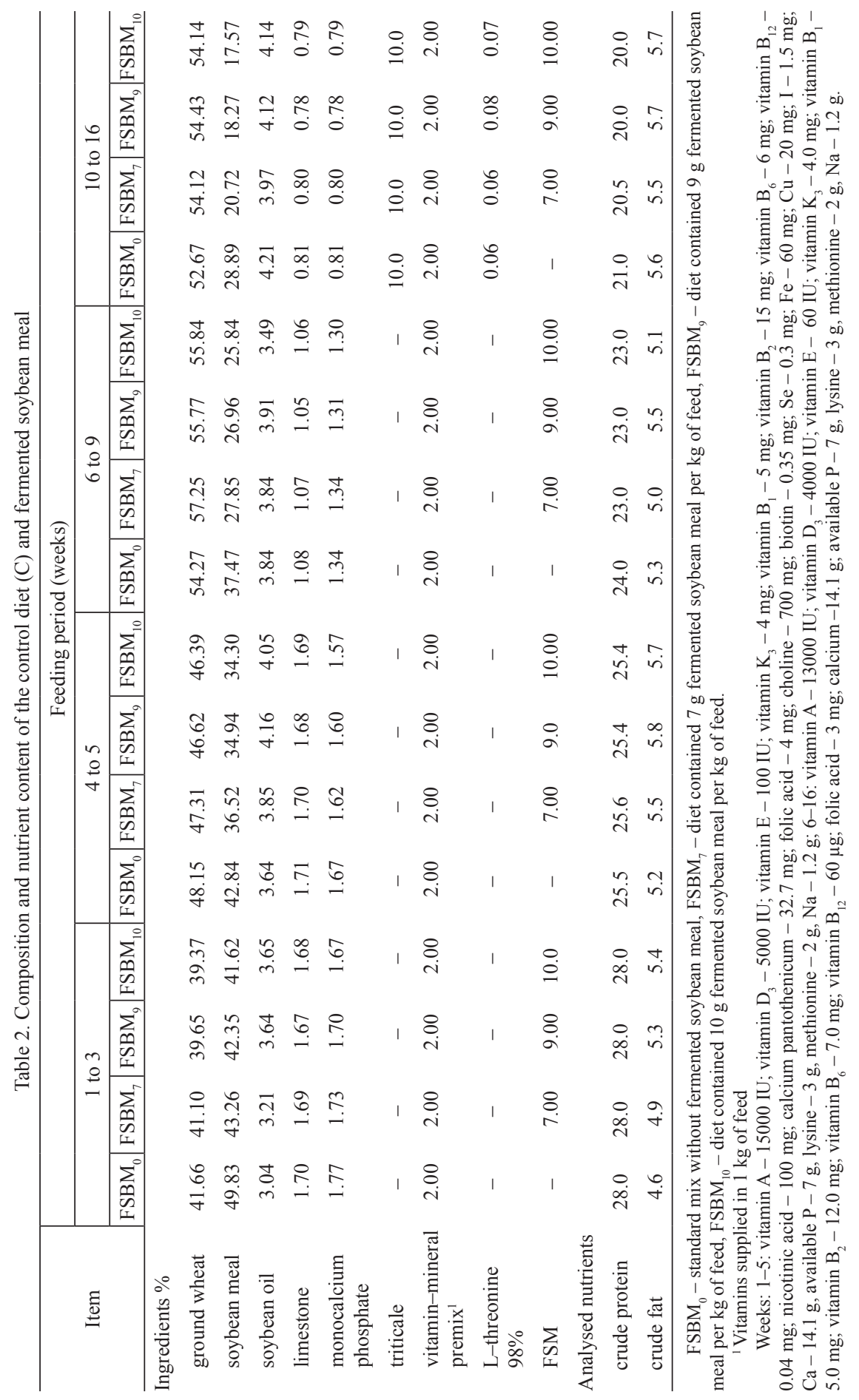




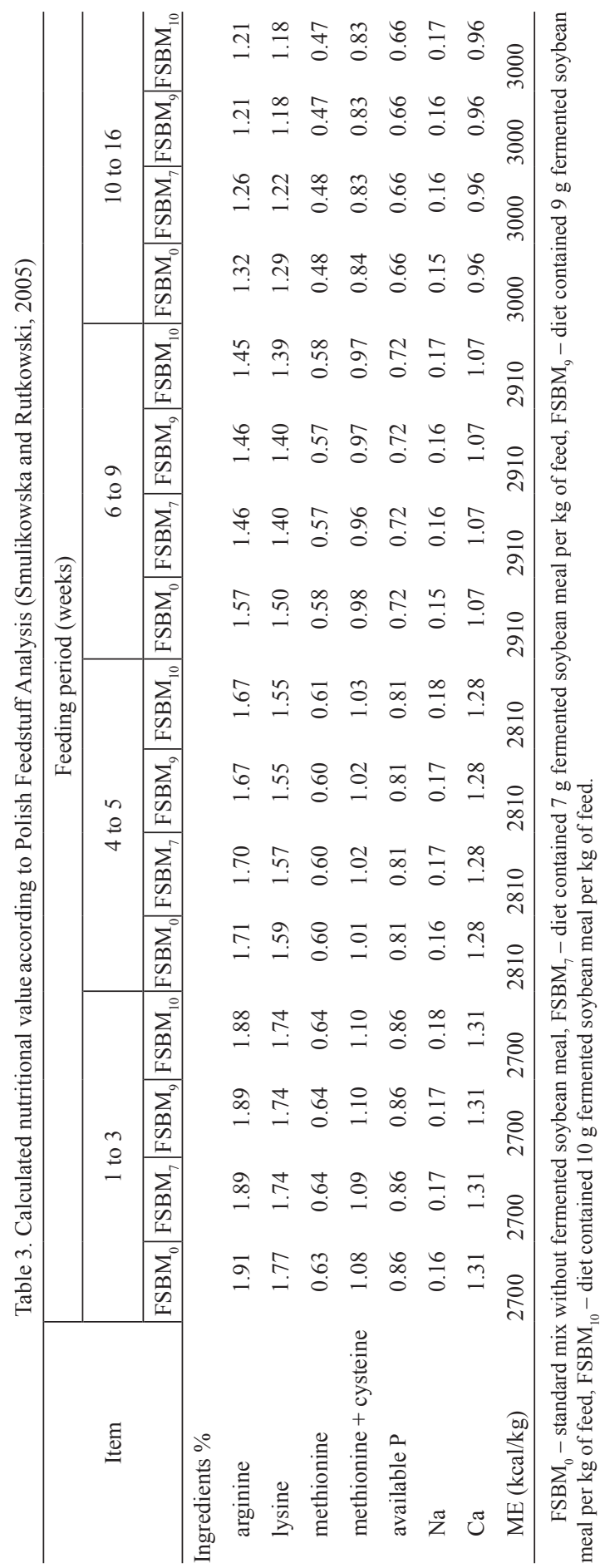




\section{Growth trial and sample collection}

At the end of each period, the body weights of turkeys, feed intake, and mortality rates were recorded and each pen of 20 birds was considered an experimental unit. Body weight gain (BWG), daily feed intake (DFI), feed conversion ratio (FCR) were calculated for each group. At the termination of the experiment, at $112 \mathrm{~d}$ of age, 9 birds representing the average BW per treatment were selected, tagged and fasted for $8 \mathrm{~h}$. Blood samples were collected from the wing vein intravitally, and birds were sacrificed by cervical dislocation. To study intestinal histology, one square centimetre of whole thickness tissue samples from the jejunum was taken. The samples were placed in 4\% buffered formaldehyde (Sigma-Aldrich Corporation, St. Louis, Missouri, USA) for $5 \mathrm{~d}$ and then stored in ethanol.

\section{Laboratory analysis}

Haemoglobin content $(\mathrm{Hb})$, haematocrit $(\mathrm{Ht})$, erythrocyte count $(\mathrm{RBC})$ and leukocyte count (WBC) in the blood were determined in an Abacus Junior Vet haematology analyser (Diatron, Hungary). Immunoglobulins: A, M and Y (IgA, IgM and IgY) and interleukin IL-6 (IL-6) in the blood were determined in an ELISA reader using assays from Elabscience Biotechnology Co., Ltd. Superoxide dismutase activity (SOD) in the erythrocytes was determined using a Ransod diagnostics kit from Randox and catalase activity (CAT) was determined according to Aebi (1984). Plasma content of glutathione (GSH + GSSG), lipid peroxides (LOOH) and malondialdehyde (MDA), as well as total antioxidant potential (FRAP) and vitamin $\mathrm{C}$, were determined according to methods described by Ognik and Wertelecki (2012). Kits developed by Cormay (PZ CORMAY S.A. Poland) were used to determine the content of the following biochemical indices in the blood plasma samples: glucose (GLU), total protein (TP), albumin (ALB), uric acid (UA), urea (UREA), bilirubin (BIL), creatinine (CREAT), total cholesterol (TC) and its fractions, i.e. high-density cholesterol (HDL) and triacylglycerols (TG); activity of the enzymes alkaline phosphatase (ALP; EC 3.1.3.1), alanine aminotransferase (ALT; EC 2.6.1.2), aspartate aminotransferase (AST; EC 2.6.1.1) and lactate dehydrogenase (LDH; EC 1.1.1.27); content of phosphorus (P), calcium (Ca), and magnesium (Mg).

Intestinal samples collected during dissection were subjected to histological evaluation. From each intestinal sample, 20 intestinal villi were selected. Their length was measured from the tip to the base, and then they were cut into slices. The depth of 20 crypts was measured as well, after which they were cut in two lengthwise. Samples of the jejunum were fixed for $24 \mathrm{~h}$ in $5 \%$ formalin, $\mathrm{pH}=7.2$. Within 24 hours the fixed tissue fragments were passed through increasing concentrations of alcohol solutions, acetone and xylene into paraffin blocks in a tissue processor (Leica TP-20). Paraffin-embedded microscope sections $5 \mu \mathrm{m}$ thick were stained with haematoxylin and eosin (HE staining). Morphometric evaluation of the length of the villi and depth of the crypts was carried out using a computer-assisted microscopic image analysis system. The system includes a light microscope (Nikon Eclipse E600) with a digital camera (Nikon DS-Fi1) and a PC with image-analysis software (NIS-Elements BR2.20, Laboratory Imaging). 


\section{Statistical analysis}

Numerical data were processed by one-way analysis of variance (ANOVA) and the results were presented as mean values for groups and standard error of mean (StatSoft Inc. 2009).

Table 4. Performance of turkey hens

\begin{tabular}{l|l|l|l|l|l|c}
\hline \multicolumn{1}{c|}{ Indicator } & FSBM $_{0}$ & FSBM $_{7}$ & FSBM $_{9}$ & FSBM $_{10}$ & SEM & P-value \\
\hline BWG (kg) & $8.874 \mathrm{~b}$ & $8.995 \mathrm{ab}$ & $9.128 \mathrm{a}$ & $9.052 \mathrm{a}$ & 0.563 & 0.047 \\
DFI (g) & 0.210 & 0.211 & 0.220 & 0.217 & 0.052 & 0.987 \\
FCR (kg/kg) & 2.482 & 2.462 & 2.532 & 2.512 & 0.264 & 0.625 \\
Mortality (\%) & 2 & 1 & 2 & 2 & NA & NA \\
\hline
\end{tabular}

$\mathrm{a}, \mathrm{b}-$ means with different letters within a row are significantly different at $\mathrm{P} \leq 0.05$; $\mathrm{SEM}-$ standard error of mean, NA - not analysed.

$\mathrm{FSBM}_{0}-$ standard mix without fermented soybean meal, $\mathrm{FSBM}_{7}$ - diet contained $7 \mathrm{~g}$ fermented soybean meal per $\mathrm{kg}$ of feed, $\mathrm{FSBM}_{9}$ - diet contained $9 \mathrm{~g}$ fermented soybean meal per $\mathrm{kg}$ of feed, $\mathrm{FSBM}_{10}$ - diet contained $10 \mathrm{~g}$ fermented soybean meal per $\mathrm{kg}$ of feed.

\section{Results}

Administration of a diet with a $9 \%$ or $10 \%$ share of FSBM led to an increase $(\mathrm{P}=0.047)$ in body weight gains of the turkeys (Table 4). Morphological measurements of the jejunum of the turkeys, presented in Table 5, showed that the fermented meals had a positive impact on the histology of the intestine. An increase in villus length was observed in the groups of turkeys from the FSBM, $\mathrm{FSBM}_{9}$ and FSBM treatments $(\mathrm{P}<0.001)$. This effect was reflected in the proportion of villus length to crypt depth, particularly in groups $\mathrm{FSBM}_{7}$ and $\mathrm{FSBM}_{10}(\mathrm{P}=0.025)$. The haematological analysis showed that the diet with fermented soybean meal, especially the FSBM treatment, had a positive impact on red blood cell parameters, as evidenced by an increase in the $R B C$ count $(\mathrm{P}=0.042), \operatorname{Hb}$ level $(\mathrm{P}=0.029)$ and $\mathrm{Ht}$ value $(\mathrm{P}=0.051)$. In the present study, in all experimental groups (especially $\mathrm{FSBM}_{10}$ ) an increase in the $\operatorname{IgM}(\mathrm{P}=0.002)$ level was observed (Table 6). A significantly $(\mathrm{P}=0.037)$ lower IgA level was noted in the blood of the turkeys from the $\mathrm{FSBM}_{7}$ treatment as compared to the $\mathrm{FSBM}_{9}$ and $\mathrm{FSBM}_{10}$ treatments. The diets with FSBM (in all treatments) contributed to a decrease in $\operatorname{IgY}$ content $(\mathrm{P}=0.002)$. An increase $(\mathrm{P}=0.003)$ in the plasma level of IL-6 was observed only in the $\mathrm{FSBM}_{9}$ and $\mathrm{FSBM}_{10}$ treatments. The data in Table 7 show that the $10 \%$ share of fermented soybean meal in the turkey feed caused a significant increase in the activity of liver enzymes AST and ALT ( $\mathrm{P}=0.023$ and $\mathrm{P}=0.001$, respectively) and in the content of GLU $(\mathrm{P}=0.048)$ and CREAT $(\mathrm{P}=0.047)$ as compared to the control. In the $\mathrm{FSBM}_{7}$ and $\mathrm{FSBM}_{9}$ treatments an increase in the content of HDL cholesterol in the plasma was noted $(\mathrm{P}=0.035)$. The use of the highest proportion of fermented soybean meal in the diet of the turkeys $\left(\mathrm{FSBM}_{10}\right)$ caused an increase in the content of $\operatorname{LOOH}(\mathrm{P}=0.026)$ and MDA $(\mathrm{P}=0.001)$, the activity of 
SOD $(\mathrm{P}<0.001)$, GPx $(\mathrm{P}=0.001)$ and CAT $(\mathrm{P}=0.003)$, a decrease in FRAP $(\mathrm{P}=0.001)$ and GSH+GSSG $(\mathrm{P}=0.033)$ in the blood as compared to the control (Table 7). In the turkeys receiving the diet with the smallest proportion of fermented soybean meal $\left(\mathrm{FSBM}_{7}\right)$, plasma levels of $\mathrm{LOOH}$ and MDA were lower $(\mathrm{P}=0.026$ and $\mathrm{P}=0.001$, respectively) than in the control, while levels of FRAP and GSH+GSSG $(\mathrm{P}=0.001$ and $\mathrm{P}=0.033$, respectively) were higher (Table 8 ).

Table 5. Measurements of the villi and crypts of the jejunum of turkey hens

\begin{tabular}{l|c|c|c|c|c|c}
\hline Indicator & FSBM $_{0}$ & FSBM $_{7}$ & FSBM $_{9}$ & FSBM $_{10}$ & SEM & P-value \\
\hline Villus height in the jejunum $(\mu \mathrm{m})$ & $1830.3 \mathrm{~b}$ & $2367.6 \mathrm{a}$ & $2195.3 \mathrm{a}$ & $2312.9 \mathrm{a}$ & 12.36 & $<0.001$ \\
Crypt depth in the jejunum $(\mu \mathrm{m})$ & $167.99 \mathrm{ab}$ & $145.85 \mathrm{~b}$ & $154.34 \mathrm{~b}$ & $186.71 \mathrm{a}$ & $6.942<0.001$ \\
Villus height/crypt depth ratio & $10.89 \mathrm{~b}$ & $16.23 \mathrm{a}$ & $14.22 \mathrm{a}$ & $12.39 \mathrm{ab}$ & 0.14 & 0.025 \\
\hline
\end{tabular}

$\mathrm{a}, \mathrm{b}-$ means with different letters within a row are significantly different at $\mathrm{P} \leq 0.05$; SEM - standard error of mean.

$\mathrm{FSBM}_{0}$ - standard mix without fermented soybean meal, $\mathrm{FSBM}_{7}-$ diet contained $7 \mathrm{~g}$ fermented soybean meal per $\mathrm{kg}$ of feed, $\mathrm{FSBM}_{9}$ - diet contained $9 \mathrm{~g}$ fermented soybean meal per $\mathrm{kg}$ of feed, $\mathrm{FSBM}_{10}$ - diet contained $10 \mathrm{~g}$ fermented soybean meal per $\mathrm{kg}$ of feed.

Table 6. Haematological and immunological parameters of the blood of turkey hens

\begin{tabular}{l|c|c|c|c|c|c}
\hline \multicolumn{1}{c}{ Indicator } & FSBM $_{0}$ & FSBM $_{7}$ & FSBM $_{9}$ & FSBM $_{10}$ & SEM & P-value \\
\hline WBC $\left(10^{9} / \mathrm{l}\right)$ & 22.81 & 20.81 & 20.95 & 21.62 & 0.894 & 0.137 \\
RBC $\left(10^{12} / \mathrm{l}\right)$ & $0.881 \mathrm{~b}$ & $0.931 \mathrm{ab}$ & $0.916 \mathrm{ab}$ & $1.012 \mathrm{a}$ & 0.047 & 0.042 \\
$\mathrm{Hb}(\mathrm{g} / \mathrm{l})$ & $83.44 \mathrm{~b}$ & $82.00 \mathrm{~b}$ & $88.50 \mathrm{ab}$ & $94.63 \mathrm{a}$ & 0.062 & 0.029 \\
$\mathrm{Ht}(\%)$ & $12.87 \mathrm{~b}$ & $13.74 \mathrm{ab}$ & $13.34 \mathrm{ab}$ & $14.50 \mathrm{a}$ & 0.033 & 0.051 \\
IgA $(\mathrm{ng} / \mathrm{ml})$ & $29.98 \mathrm{ab}$ & $21.11 \mathrm{~b}$ & $31.38 \mathrm{a}$ & $31.58 \mathrm{a}$ & 0.055 & 0.037 \\
IgY $(\mathrm{ng} / \mathrm{ml})$ & $860.1 \mathrm{a}$ & $784.5 \mathrm{~b}$ & $711.8 \mathrm{c}$ & $727.9 \mathrm{~b}$ & 0.752 & 0.002 \\
IgM $(\mathrm{ng} / \mathrm{ml})$ & $637.8 \mathrm{c}$ & $882.2 \mathrm{~b}$ & $996.4 \mathrm{ab}$ & $1150.1 \mathrm{a}$ & 1.094 & $<0.001$ \\
IL-6 $(\mathrm{ng} / \mathrm{ml})$ & $4.231 \mathrm{~b}$ & $4.134 \mathrm{~b}$ & $5.338 \mathrm{a}$ & $5.142 \mathrm{a}$ & 0.483 & 0.003 \\
\hline
\end{tabular}

$\mathrm{a}, \mathrm{b}-$ means with different letters within a row are significantly different at $\mathrm{P} \leq 0.05$; $\mathrm{SEM}-$ standard error of mean.

WBC - leukocytes, RBC - erythrocytes, $\mathrm{Hb}$ - haemoglobin, $\mathrm{Ht}$ - haematocrit, $\mathrm{IgA}$ - immunoglobulin A, IgY - immunoglobulin Y, IgM - immunoglobulin M, IL-6 - interleukin 6.

$\mathrm{FSBM}_{0}$ - standard mix without fermented soybean meal, $\mathrm{FSBM}_{7}$ - diet contained $7 \mathrm{~g}$ fermented soybean meal per $\mathrm{kg}$ of feed, $\mathrm{FSBM}_{9}$ - diet contained $9 \mathrm{~g}$ fermented soybean meal per $\mathrm{kg}$ of feed, $\mathrm{FSBM}_{10}-$ diet contained $10 \mathrm{~g}$ fermented soybean meal per $\mathrm{kg}$ of feed. 


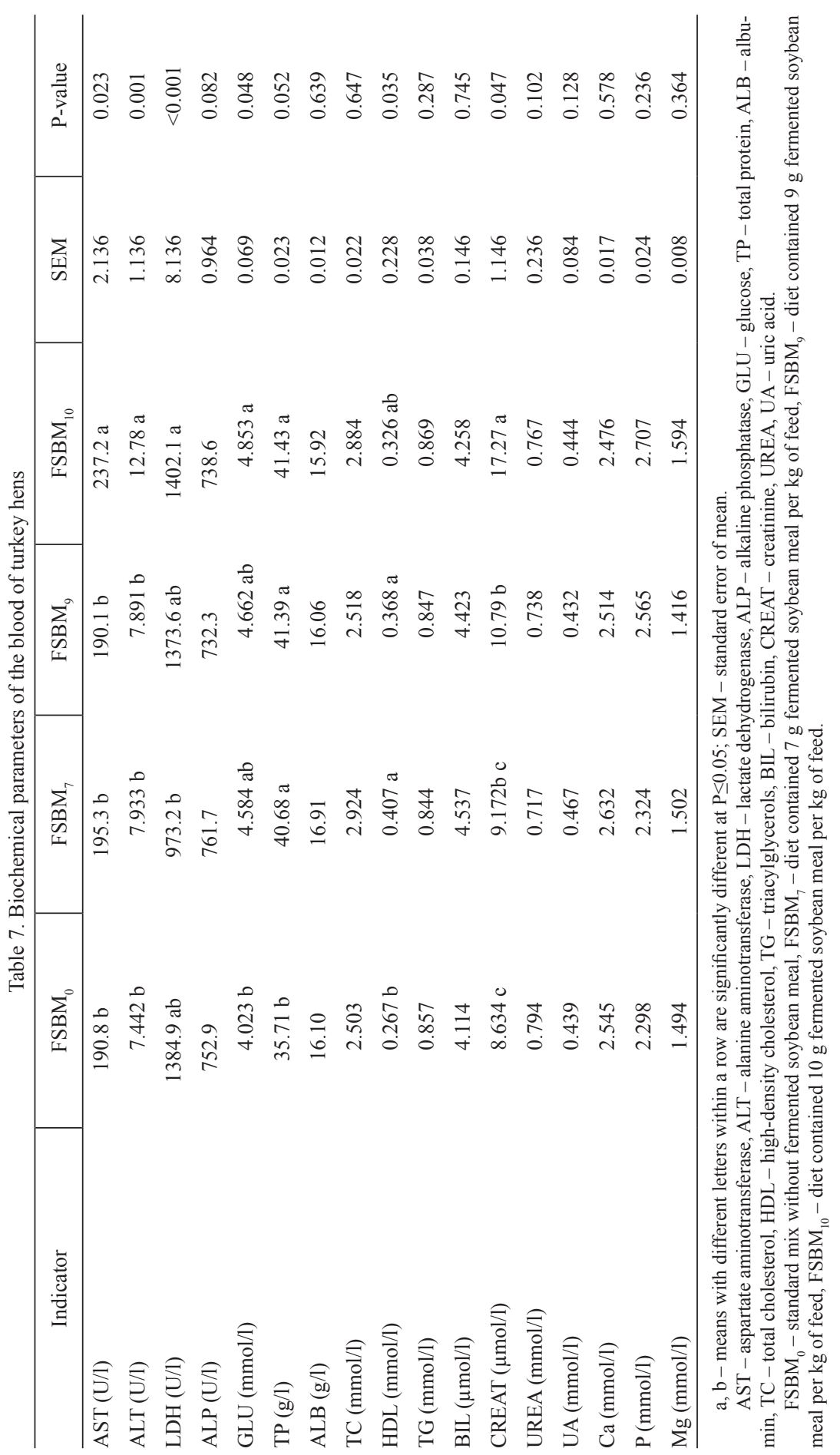


Table 8. Redox parameters of the blood of turkey hens

\begin{tabular}{l|c|c|c|c|c|c}
\hline \multicolumn{1}{c}{ Indicator } & FSBM $_{0}$ & FSBM $_{7}$ & FSBM $_{9}$ & FSBM $_{10}$ & SEM & P-value \\
\hline LOOH $(\mu \mathrm{mol} / \mathrm{l})$ & $89.96 \mathrm{~b}$ & $75.98 \mathrm{c}$ & $91.43 \mathrm{~b}$ & $103.2 \mathrm{a}$ & 2.136 & 0.026 \\
$\mathrm{MDA}(\mu \mathrm{mol} / \mathrm{l})$ & $0.689 \mathrm{~b}$ & $0.639 \mathrm{c}$ & $0.862 \mathrm{ab}$ & $1.081 \mathrm{a}$ & 0.431 & 0.001 \\
$\mathrm{SOD}(\mathrm{U} / \mathrm{g} \mathrm{Hb})$ & $1896.2 \mathrm{~b}$ & $1904.6 \mathrm{~b}$ & $2861.7 \mathrm{~b}$ & $3157.2 \mathrm{a}$ & 116.9 & $<0.001$ \\
$\mathrm{GPx}(\mathrm{U} / \mathrm{g} \mathrm{Hb})$ & $95.63 \mathrm{~b}$ & $114.2 \mathrm{ab}$ & $99.54 \mathrm{~b}$ & $135.24 \mathrm{a}$ & 1.145 & 0.001 \\
$\mathrm{CAT}(\mathrm{U} / \mathrm{g} \mathrm{Hb})$ & $485.6 \mathrm{c}$ & $459.7 \mathrm{c}$ & $534.2 \mathrm{~b}$ & $614.2 \mathrm{a}$ & 6.135 & 0.003 \\
FRAP $(\mu \mathrm{mol} / \mathrm{l})$ & $115.2 \mathrm{~b}$ & $136.9 \mathrm{a}$ & $108.84 \mathrm{~b}$ & $88.65 \mathrm{c}$ & 3.695 & 0.001 \\
$\operatorname{GSH}+\mathrm{GSSH}(\mu \mathrm{mol} / \mathrm{l})$ & $0.186 \mathrm{~b}$ & $0.236 \mathrm{a}$ & $0.164 \mathrm{bc}$ & $0.128 .6 \mathrm{c}$ & 0.139 & 0.033 \\
Vit. C $(\mu \mathrm{mol} / \mathrm{l})$ & 0.842 & 0.856 & 0.812 & 0.832 & 0.268 & 0.268 \\
\hline
\end{tabular}

$\mathrm{a}, \mathrm{b}, \mathrm{c}-$ means with different letters within a row are significantly different at $\mathrm{P}<0.05$; SEM - standard error of mean.

$\mathrm{LOOH}$ - lipid peroxides, MDA - malondialdehyde, SOD - superoxide dismutase, GPx - gluthatione peroxidase, CAT - catalase, FRAP - total antioxidant status in plasma, GSH + GSSG - total glutathione.

$\mathrm{FSBM}_{0}$ - standard mix without fermented soybean meal, $\mathrm{FSBM}_{7}$ - diet contained $7 \mathrm{~g}$ fermented soybean meal per $\mathrm{kg}$ of feed, $\mathrm{FSBM}_{9}$ - diet contained $9 \mathrm{~g}$ fermented soybean meal per $\mathrm{kg}$ of feed, $\mathrm{FSBM}_{10}-$ diet contained $10 \mathrm{~g}$ fermented soybean meal per $\mathrm{kg}$ of feed.

\section{Discussion}

In the current study the diet containing fermented soybean meal had no effect on feed intake and feed conversion ratio, but turkeys fed the diet with $9 \%$ and $10 \%$ FSBM achieved higher final body weight than control birds. Our results corroborate those of Feng et al. (2007 a) who observed growth-promoting activity of FSBM in chickens.

It is likely that the improvement of growth in chicks that had been fed some FSBMs may be associated with a decrease of the content of anti-nutritional factors or changes in peptide size by fermentation. During fermentation, soybean proteins are converted to better available, low-molecular-weight and water-soluble peptides. This process reduces contents of trypsin inhibitors, phytic acid, oligosaccharides and allergenic proteins which interfere with digestion, absorption, and utilization of nutrients (Liu et al., 2017). The post-extraction fermentation process of soybean meal used to compose our blend made the level of trypsin inhibitors decreased. Feng et al. (2007 a) has revealed that inclusion of FSM to the diet contributed to significant elevation of the activities of digestive enzymes (trypsin, lipase, and protease) in intestinal contents of broiler chickens.

Numerous studies conducted in recent years have shown that the inclusion of fermented protein products in animal diets has a beneficial effect on growth performance (Drażbo et al., 2018 a, b). The improvement of the growth may be also attributed to beneficial changes in microbial profile in gastrointestinal tract (GIT). The results of the present study indicate that a diet with a $9 \%$ or $10 \%$ share of fermented soybean meal had a beneficial effect on body weight gains, which could have been associated with their bactericidal and/or bacteriostatic effect on the microbiome of 
the gastrointestinal tract (Dhama et al., 2011). It is worth noting that after the bacterial fermentation process, the final product was enriched with live cultures of probiotic lactic acid bacteria (LAB), which could colonize the GIT of turkeys. By producing volatile fatty acid and bacteriocins, LAB create conditions unfavorable for growth of undesirable bacteria including pathogenic bacteria strains. Engberg et al. (2009) in the experiment on laying hens and Jazi et al. (2017) in the experiment on chickens have shown that feeding fermented products increased population of desirable microbiota and decreased population of pathogenic coliform bacteria in the intestine. It has been proven that microbial activity in the GIT significantly influences growth performance and health condition of poultry (Niba et al., 2009).

Histomorphological analyses have shown that partial replacement of soybean meal by fermented soybean meal in turkeys diet contributed to an increase of villus height and villus height/crypt depth ratio. It is worth noting that fermentation of soybean meals significantly decreases level of allergenic proteins: glycinin and B-conglycinin. They induce hypersensitivity reactions, promoting intestinal villus atrophy and decreasing the ratio between the villi length and crypt depth (Wang et al., 2012).

The integrity of the small intestine is usually expressed by the height of the intestinal villi and the depth of the crypts. It is commonly known that longer intestinal villi lead to enlargement of absorptive area, thus improving nutrient absorption (Cui et al., 2018; Hou et al., 2013). According to Montagne et al. (2003) an increase in the villus height to crypt depth ratio is a potent indicator of absorptive capability of the small intestine. Studies conducted by other authors have revealed that diets with fermented products positively influenced small intestine structure and functions in poultry which results in improved performance parameters (Drażbo et al., $2018 \mathrm{a}, \mathrm{b}$; Jazi et al., 2018). Scholten et al. (2002) observed that villus height, villus shape and villus to crypt ratio were increased in swine fed with fermented diet, which may be due to higher level of lactic acid and other short chain fatty acids present in fermented feed. The increased villus height and better villus height/crypt depth ratio may be a consequence of an increased number of beneficial microbes (Xu et al., 2003). The improvement in the morphological parameters of the intestine contributed to greater absorption of nutrients and higher body weight gains in the birds, as well as a better feed conversion ratio. It has been proposed that feed nutrients utilisation is strongly related to the intestinal structure and villus health, and the small intestine is known as a major digestion and absorption site of dietary nutrients (Pluske et al., 1996). The improvement of intestinal morphology in the current study might be mostly due to the removal of antinutritional factors and the degradation of large-size protein to small-size peptides in soybean meal after fermentation (Hu et al., 2016). The live microbes in the fermented feed may also act as probiotic to enhance the humoral immune response (Jazi et al., 2018). The lactic and acetic acid produced by the bacteria in the fermented feed creates an acidic environment about $\mathrm{pH}=4$. At this level of acidity, molecules of acid can enter the bacteria through their cell membranes, and the increased acidity within the cells interferes with enzymatic processes, killing the bacteria (Heres et al., 2003).

The blood haematological and biochemical as well as immunological indices were determined in order to evaluate the influence of experimental diets on health status 
of birds. The results of red blood cells system parameters indicated that fermented soybean meal, especially supplemented at $10 \%$ level contributed to an increase in the RBC count, Hb level and Ht value. This effect may be related to high content of Lactobacilli in the fermented feed. The products of their metabolism, e.g. some Bgroup vitamins, polyamines and arginine, are factors stimulating erythropoiesis and haemopoiesis. It can be suggested that the increased villus height was accompanied by an increasing proliferation of undifferentiated cells and their maturation into full enterocytes (Gnikpo et al., 2016). Lactic acid and polysaccharides produced by Lactobacilli can modulate the immune response, which can be seen in increased production of immunoglobulins or modulation of cytokine secretion (Matsuzaki and Chin, 2000). In addition, the fermentation process enriches product in bioactive peptides, which may improve immune function (Xue et al., 2009). Feng et al. (2007 a) showed that fermented soybean meal had beneficial effect on the performance parameters of chickens and increased the serum level of $\operatorname{IgA}$ and IgM. In experiments conducted by $\mathrm{Xu}$ et al. (2011), ducks fed fermented soybean meal had higher blood levels of IgA and IgG. The results of the present study indicated that diet with $9 \%$ and $10 \%$ FSBM contributed to an increase in pro-inflammatory interleukin- 6 in the blood. Moreover, fermented soybean meal added into the diet of turkeys (in all treatments) caused an increase in the level of serum IgM. In turn, a decrease in serum IgY level was also observed. It is worth noting that in poultry, immunoglobulin $\mathrm{Y}$ is the functional equivalent to immunoglobulin G. It is known that soybean proteins (glycinin and $\beta$-conglycinin, and trypsin inhibitor) may induce IgG-mediated hypersensitivity response (Nowak-Węgrzyn et al., 2015). The decrease in serum IgY concentration may suggest that fermentation effectively reduced contents of allergenic soybean compounds. Similar results, as a consequence of replacement of soybean meal by fermented soybean meal in diet were observed in pigs (Liu et al., 2007).

An increase of IL- 6 concentration observed in the group receiving the highest share of FSBM in the feed ration is not a favourable phenomenon, because according to Liu et al. (2017) it stimulates, mediates and promotes the occurrence of inflammatory bowel disease. The results of the current study revealed that diet with FSBM caused an increase in the concentration of total protein in the plasma of turkeys. A similar result, indicating that fermented rapeseed meal increased the TP level in the blood of chickens, was obtained by $\mathrm{Hu}$ et al. (2016). This effect may have been linked to the beneficial effect of the fermentation process on the digestibility and bioavailability of amino acids in the feed (Feng et al., $2007 \mathrm{~b}$ ). A beneficial effect, observed in the $\mathrm{FSBM}_{7}$ and $\mathrm{FSBM}_{9}$ treatments was an increase in the HDL cholesterol content. Similarly, an increase in the level of this cholesterol fraction was also observed by Hung et al. (2008) following administration of fermented soybean meal to piglets. The diet with 10\% FSBM led to an increase in liver enzymes activity: AST and ALT which should be considered an adverse effect. Daoguang et al. (2015) reported an increase in ALP activity in the plasma of piglets receiving feed with FSBM in the amount of $3 \%, 6 \%$ and $9 \%$. The increase in the GLU and CREAT levels in the blood of the turkeys receiving feed with $10 \%$ fermented soybean meal indicates that it may have a negative effect on liver and kidney function. Similarly to the present study, an increase in the glucose level in broiler chickens receiving $10 \%$ 
addition of fermented rapeseed meal was reported by $\mathrm{Hu}$ et al. (2016). The elevated glucose level found in the FSBM 10 group may have been caused by a weaker liver condition in these birds. In this situation, gluconeogenesis may be impaired and the process of disintegration of replacement sugars may increase, hence their high level in the blood. In addition, such a condition is observed in the situation of impaired glucose tolerance, the effect of which is an increase in blood glucose concentration and a decrease in the sensitivity of cells to insulin. Insulin deficiency then causes increased lipolysis, increases the oxidation of fatty acids, inhibits glycolysis, which additionally strengthens and intensifies insulin resistance (Dam, 2008).

Analysis of redox parameters of turkeys' blood showed that diet with 9 and $10 \%$ fermented soybean meal caused an increase in the content of lipid peroxides and malondialdehyde as well as in the activity of SOD, GPx and CAT. These changes were accompanied by a decrease in FRAP and GSH+GSSG content in the blood. Our study showed that the fermented soybean meal used in the feed contained nutrients with antioxidant properties (vitamin C and polyphenols) (Adetuyi and Ibrahim, 2014). Drażbo et al. (2018 b) found fermented rapeseed cake to stimulate the antioxidant system of turkeys, which was reflected in a decrease in the concentrations of LOOH and MDA, and an increase in the FRAP and the concentration of GSH + GSSG in blood plasma, compared with the control group. A study by Liu et al. (2017) showed that biologically active peptides of soybean, exhibit strong antioxidant properties. Qingbao et al. (2007) added soy isoflavones to the diet of chickens in the amount of $10,20,30 \mathrm{mg} / \mathrm{kg}$ and noted a significant improvement in the growth performance of the birds receiving the lowest and the intermediate dose of the supplement, but observed no effect on antioxidant status in the birds. Our study showed that increasing the share of fermented soybean meal in a diet of turkeys (treatments $\mathrm{FSBM}_{9}$ and $\mathrm{FSBM}_{10}$ ) had an adverse effect on indicators of antioxidant status. From a practical perspective, an increase in parameters indicating induction of oxidation mechanisms is an adverse phenomenon, as it may have a negative effect on the quality of the turkey meat (Tavárez et al., 2018).

\section{Conclusions}

The study showed that by including fermented soybean meal in feed for turkeys at $7 \%$, the histology of the small intestine can be improved and the body's immune and antioxidant systems can be stimulated. The use of higher levels of FSBM $(9 \%$ and 10\%) in the turkeys' diet improves the growth performance, but causes adverse oxidation reactions in the body and an increase in IL-6 levels that can potentially stimulate inflammatory processes in the gut.

\section{References}

A det uy i F.O., I b r a h i m T.A. (2014). Effect of fermentation time on the phenolic, flavonoid and vitamin C contents and antioxidant activities of okra (Abelmoschus esculentus) seeds. NIFOJ, 32: $128-137$.

A e b i H. (1984). Catalase in vitro. Meth. Enzymol., 105: 121-126. 
Cu i Y., Wang Q., S un R., Gu o L., Wang M., J i a C., X u J., W u R. (2018). Astragalus membranaceus (Fisch.) Bunge repairs intestinal mucosal injury induced by LPS in mice. BMC Complement Altern. Med., 18: 230-236.

D a m R.M. (2008). Coffee consumption and risk of type 2 diabetes, cardiovascular diseases, and cancer. Appl. Physiol. Nutr. Metab., 33: 1269-1283.

Da o guang X., Jianguo Q., Yu fen Y. (2015). Effects of fermented soybean meal on growth performance, serum biochemical index and fecal compounds in fattening pig. Swine Prod. 5: 25-43.

Dh a m a K., Verma V., S aw ant P.M., Tiw ari R., Vaid R.K., Chauhan R.S. (2011). Applications of probiotics in poultry: enhancing immunity and beneficial effects on production performances and health - a review. J. Immuol. Immunopath., 13: 1-19.

Drażbo A., Mikulski D., J a nk ow ski J., Z duńczyk Z. (2018 a). The effect of diets containing raw and fermented faba beans on gut functioning and growth performance in young turkeys. J. Anim. Feed Sci., 27: 65-73.

Drażb o A., O gnik K., Z a w or ska A., F erenc K., J a n k ow sk i J. (2018 b). The effect of raw and fermented rapeseed cake on the metabolic parameters, immune status, and intestinal morphology of turkeys. Poultry Sci., 97: 3910-3920.

Engberg R.M., Hammershøj M., Johan sen N.F., Abous ekken M.S., S teen feldt S., Jensen B.B. (2009). Fermented feed for laying hens: effects on egg production, egg quality, plumage condition and composition and activity of the intestinal microflora. Brit. Poultry. Sci., 50: 228-239.

F eng J., Li u X., Lu Y.P., Li u Y.Y. (2007 a). Effects of fermented soybean meal on growth, serum parameters and the intestine morphology in weaned piglet. Chin. J. Anim. Nutr., 1: 58-74.

F e n g J., L i u Z.R., X u Y., L i u Y., L u Y.P. (2007 b). Effects of Aspergillus oryzae 3.042 fermented soybean meal on growth performance and plasma biochemical parameters in broilers. Anim. Feed Sci. Technol., 134: 235-242.

Gnikpo A.F., Chrysostome C.A., Houndonougbo M.F., Adenile D.A., Dougnon J., L ib a n i o D. (2016). Efficacy of feed ingredient with probiotics properties, on the growth performance and health of giant white bouscat red eye rabbits. J. Anim. Vet. Adv., 6: 889-889.

Heres L., Wagenaar J.A., Van Knapen F., Urlings B. (2003). Passage of Salmonella through the group and gizzard of broiler chickens fed with fermented liquid feed. Avian Pathol., 32: 173-181.

H ong K.J., L e e C.H., K i m S.W. (2004). Aspergillus oryzae 3.042GB-107 fermentation improves nutritional quality of food soybeans and feed soybean meals. J. Med. Food, 7: 430-434.

H o u Y., Wang L., Y i D., D ing B., Yang Z., Li J., Ch e n X., Q i u Y., Wu G. (2013). N-acetylcysteine reduces inflammation in the small intestine by regulating redox, EGF and TLR4 signaling. Amino Acids, 45: 513-522.

Hu Y., Wang Y., Li A., Wang Z., Z hang X., Yun T. (2016). Effects of fermented rapeseed meal on antioxidant functions, serum biochemical parameters and intestinal morphology in broilers. Food Agric. Immunol., 27: 182-193.

Hung A., Su T., Lis o C. (2008). Effect of probiotic combination fermented soybean meal on growth performance lipid metabolism and immunological response of growing finishing pigs. Asian J. Anim. Vet. Adv., 3: 421-436.

H u r S.J., L e e S.Y., K i m Y.C., Choi I., G e un-B a e K i m G.B. (2014). Effect of fermentation on the antioxidant activity in plant-based foods. Food Chem., 160: 346-356.

Jazi V., Boldaji F., Dastar B., Hashemi S.R., Ashayerizadeh A. (2017). Effects of fermented cottonseed meal on the growth performance, gastrointestinal microflora population and small intestinal morphology in broiler chickens. Brit. Poultry Sci., 58: 402-408.

Jazi V., Ashayerizadeh A., Toghyani M., Shabani A., Tellez G., Toghyani M. (2018). Fermented soybean meal exhibits probiotic properties when included in Japanese quail diet in replacement of soybean meal. Poultry Sci., 97: 2113-2122.

K im S.W., Van Heugten E., Ji F., L e e C.H., Mate o R.D. (2010). Fermented soybean meal as a vegetable protein source for nursery pigs: I. Effects on growth performance of nursery pigs. J. Anim. Sci., 88: 214-224.

Li u X., Feng J., Xu Z., Lu Y., Li u Y. (2007). The effects of fermented soybean meal on growth performance and immune characteristics in weaned piglets. Turk. J. Vet. Anim. Sci., 31: 341-334. 
L i u H.M., L i a o J.F., L e e T.Y. (2017). Farnesoid X receptor agonist GW4064 ameliorates lipopolysaccharide-induced ileocolitis through TLR4/MyD88 pathway related mitochondrial dysfunction in mice. Biochem. Biophys. Res. Commun., 490: 841-848.

Mathivanan R., S e lvaraj P., N anjappan K. (2006). Feeding of fermented soybean meal on broiler performance. Int. J. Poult. Sci., 5: 868-872.

Mats uzaki K., C h in J. (2000). Modulating immune responses with probiotic bacteria. Immunol. Cell Biol., 78: 67-73.

Missotten J., Michiels J., Degroote J., De Smet S. (2015). Fermented liquid feed for pigs: an ancient technique for the future. J. Anim. Sci. Biotechnol., 6: 4-9.

Montagne L., Pluske J.R., Hamps on D.J. (2003). A review of interactions between dietary fibre and the intestinal mucosa, and their consequences on digestive health in young non-ruminant animals. Anim. Feed Sci. Technol., 108: 95-117.

$\mathrm{N}$ i b a A.T., B e a 1 J.D., K u d i A.C. (2009). Bacterial fermentation in the gastrointestinal tract of nonruminants: influence of fermented feeds and fermentable carbohydrates. Trop. Anim. Health Prod., 41: 1393-1407.

Nowak-W ęgrzyn A., Katz Y., Mehr S.S., K ol etzk o S. (2015). Non-IgE-mediated gastrointestinal food allergy. J. Allergy Clin. Immunol., 135: 1114-1124.

O g n i k K., We r te le c ki T. (2012). Effect of different vitamin E sources and levels on selected oxidative status indices in blood and tissues as well as on rearing performance of slaughter turkey hens. J. Appl. Poult. Res., 21: 259-271.

Plus k e J.R., Willi a m s I.H., A herne F.X. (1996). Maintenance of villous height and crypt depth in piglets by providing continuous nutrition after weaning. Anim. Sci., 62: 131-144.

Q ing ba o A., D e y i L., Q i ong G., B e ny u H., F e i Z. (2007). Effect of soybean isoflavones on antioxidant activity in crossbred chickens. J. Anhui Agric. Univ., 9: 20-25.

Scholten R.H.J., van der Peet-Schwering C.M.C., den Hartog L.A., Balk M., S chrama J.W., Verstegen M.W. (2002). Effect of lactic acid fermented soyabean meal on the growth performance, intestinal microflora and morphology of weaned piglets. Anim. Sci., 80: 1179-1186.

S m u lik ow s k a S., R u t k ow s k i A. (2005). Editors. Recommended allowances and nutritive value of feedstuffs. Poultry feeding standards (in Polish). 4th ed. The Kielanowski Institute of Animal Physiology and Nutrition, PAS, Jabłonna (Poland).

Tavárez M.A., B ol er D.D., B es s N., Z ha o J., Yan F., Dilger A.C., M cke ith F., Kille fer J. (2018). Effect of antioxidant inclusion and oil quality on broiler performance, meat quality, and lipid oxidation. Poultry Sci., 90: 922-930.

W a n g L.C., W e n C., J i a n g Z.Y., Z h o u Y.M. (2012). Evaluation of the partial replacement of highprotein feedstuff with fermented soybean meal in broiler diets. J. Appl. Poult. Res., 21: 849-855.

X u Z.R., Hu C.H., Xi a M.S., Zhan X.A., Wang M.Q. (2003). Effects of dietary fructooligosaccharide on digestive enzyme activities, intestinal microflora and morphology of male broilers. Poultry Sci., 82: 648-654.

X u F., Li L., X u J., Q i a n K., Z h ang Z., L i ang Z. (2011). Effects of fermented rapeseed meal on growth performance and serum parameters in ducks. Asian-Australas. J. Anim. Sci., 24: 678-684.

$\mathrm{X}$ u e Z.H., Yu W.C., W u M.C., Wang J.H. (2009). In vivo antitumor and antioxidative effects of a rapeseed meal protein hydrolysate on an S180 tumor-bearing murine model. Biosci. Biotechnol. Biochem., 73: 2412-2415.

Zhang H.Y., Y i J.Q., P i a X.S., L i P.F., Zeng Z.K., Wang D., L i u L., Wang G.Q., Ha n X. (2013). The metabolizable energy value, standardized ileal digestibility of amino acids in soybean meal, soy protein concentrate and fermented soybean meal, and the application of these products in early-weaned piglets. Asian-Australas. J. Anim. Sci., 26: 691-699.

Received: 24 I 2019

Accepted: 11 VI 2019 